\title{
Design, Development and Evaluation of Self Nanoemulsifying Drug Delivery System of Garlic Oil using Capryol PGMC
}

\author{
Priyanka Sangar1, Bandgar Sandip ${ }^{1, *}$, Shelake Sardar², Patil Pravin', Bhagwat Durgacharan ${ }^{3}$, \\ Patil Shitalkumar ${ }^{1}$
}

1Department of Pharmaceutics, Ashokrao Mane College of Pharmacy, Peth-Vadgaon, Kolhapur, Maharashtra, INDIA. 2Department of Pharmaceutics, Ashokrao Mane Institute of Pharmacy, Ambap, Maharashtra, INDIA.

${ }^{3}$ Department of Pharmaceutics, Bharati Vidyapeeth College of Pharmacy, Kolhapur, Maharashtra, INDIA.

\begin{abstract}
Introduction: At present days there was considerable attention has been taken to develop lipid based pharmaceutical preparation which improves solubility as well as permeability leads to improve oral bioavailability of poorly water soluble drug with a system known as self nano-emulsifying drug delivery system. Materials and Methods: The SNEDDS of garlic oil was prepared by using oleic acid as oil, capryol PGMC as a surfactant and ethanol as a co-surfactant, as the garlic oil shows better solubility in these excipients which is find out by constructing pseudo-ternary phase diagram. The $\mathrm{Km}=3$ was selected for the preparation of SNEDDS of garlic oil because it shows better nanoemulsion region as compared to $\mathrm{Km}=1$ and 2. Discussion: The formulated SNEDDS of garlic oil was evaluated for physical characterization, thermodynamic stability, rheology study, globule size and zeta potential, dispersibility study, cloud point determination, \% transmittance, drug content, FTIR study and in vitro drug release study. Three batches of SNEDDS of garlic oil was formulated using $\mathrm{Km}$ value 3 which cover maximum nanoemulsion region, containing oleic acid (solubility 57.53 \pm 0.45), Capryol PGMC (solubility 59.80 \pm 0.82 ) and ethanol (solubility $49.83 \pm 0.30$ ). Based on the compatibility study, optimum globule size $(177.2 \mathrm{~nm})$, minimum polydispersity $(0.386)$, higher drug content $(90.89$ $\pm 0.68)$ and higher drug release $(98.85 \%)$, batch F2 was optimized. Conclusion: The bioavailability problem can be overcome by the Self nano- emulsifying drug delivery system, which presents the more drug in solubilized form in the body as compared with other conventional drug delivery systems.
\end{abstract}

Key words: Self Nanoemulsifying Drug Delivery System, Garlic oil, Pseudo ternary phase diagram, Capryol PGMC, poorly water soluble drug.

\section{INTRODUCTION}

Garlic, botanically known as Allium sativum Linn. a member of Liliaceae family is one of the earliest documented example of plants employed for the treatment of diseases and maintenance of health. ${ }^{1}$ Garlic oil is best known for its number of medicinal values such as anti-atherosclerosis, blood lipid and sugar modulation, antifungal, antimicrobial, anti-thrombolic, cardiovascular disease treatment and stimulation of immune system. ${ }^{2}$ However, the application of garlic oil in the food industry is limited due to its volatility, strong odour, insolubility in water and low physicochemical stability. ${ }^{3}$ To overcome these problems various methods are listed in the literature which include incorporation of hydrophilic excipients, solid dispersion, micellar solublization, microemulsion etc. But in recent years considerable attention has been made to develop lipid based pharmaceutical preparation as it improves not only solubility but also permeability which leads to improve oral bioavailability of poorly water soluble
Submission Date: 11-09-2018; Revision Date: 14-06-2019; Accepted Date: 16-10-2019

DOI: 10.5530/ijper.53.4s.148 Correspondence:

Mr. Sandip Akaram Bandgar, Department of Pharmaceutics, Ashokrao Mane College of Pharmacy, Peth-Vadgaon, Kolhapur, Maharashtra-416112, INDIA.

Phone: +91 8600009719

E-mail: bandgarsandip21@ gmail.com

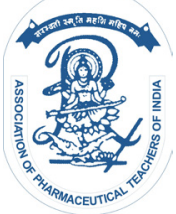

www.ijper.org 
drugs, such a system is known as Self Nanoemulsifying Drug Delivery System (SNEDDS). ${ }^{4}$

Self Nanoemulsifying Drug Delivery Systems (SNEDDS) are regarded as anhydrous forms of the nanoemulsion. SNEDDS are homogenous liquid mixtures consisting of drug, natural or synthetic oil, surfactant and co-surfactant that have a rival ability of spontaneously forming fine oil-in-water $(\mathrm{O} / \mathrm{W})$ nanoemulsions of size about $200 \mathrm{~nm}$ or less, upon dilution with water. These preparations are thermodynamically stable and transparent or translucent system. Nanosized dispersion of nanoemulsion was stabilized by the addition of surfactants and co-surfactants. SNEDDS are also known as nanoemulsion, miniemulsion, ultrafine emulsion or submicron emulsion. These systems were formulated mainly by using medium chain triglycerides, oils and non-ionic surfactant, which is important in oral ingestion. SNEDDS are one of the stable nanoemulsion and it provides a large interfacial area for partitioning of drug between oil and aqueous phase, thereby improves the rate of drug dissolution and increases bioavailability of the drug formulation. SNEDDS are the most preferred drug delivery system due to their stability, practicability of easy oral administration and ability to enhance drug self emulsification inside the gut. ${ }^{5,6}$

Thus, utilizing SNEDDS as a promising technology to overcome the problems of low bioavailability leads to develop a drug with improved solubility as well as improved physiochemical stability. ${ }^{7}$ Hence, SNEDDS of garlic oil will control different aspects of drug efficacy such as pharmacokinetics, bioavailability, targeted delivery, non-specific toxicity and immunogenicity and will be beneficial as suitable dosage form which results in better patience compliance and improved therapeutics. ${ }^{8,9}$

\section{MATERIALS AND METHODS}

Garlic oil (Sanket Enterprises, Mumbai), Oleic acid (Molychem, Mumbai), Capryol PGMC (Gattefosse, France), Ethanol and Methanol (S. D. fine Chemicals, Mumbai). All other materials or chemicals used were of analytical grade.

\section{Selection and screening of drug components}

For the selection of suitable components with good solubilizing capacity for garlic oil, saturation solubility of garlic oil was examined in various oils (oleic acid, cotton seed oil, almond oil, castor oil), surfactant (Capryol PGMC, Labrafac PG, tween 20, span 80, cremophore EL) and co-surfactants (Ethanol, propylene glycol, PEG 200, glycerol). In this solubility study the excess amount of drug i.e. garlic oil was added into screw caped glass vials containing two $\mathrm{ml}$ of each excipients followed by sealed vials. The sealed vials were kept in sonicator for $2 \mathrm{~h}$. after that the mixture was kept in water bath at $40^{\circ} \mathrm{C}$ for $24 \mathrm{~h}$ and then these vials were centrifuged at $15000 \mathrm{rpm}$ for $30 \mathrm{~min}$. The samples were collected and filtered using a membrane filter ( 0.45 micro meter). The filtrate was suitably diluted with methanol and drug concentration was obtained by using UV Visible spectrophotometer. ${ }^{10}$

\section{Construction of pseudo ternary phase diagram}

The pseudo ternary phase diagram was constructed without garlic oil to recognize the maximum selfemulsifying domain existence and to specify the optimal ratio of oil, surfactant and co-surfactant for the SNEDDS formulations. The pseudo ternary phase diagrams were constructed by drop wise addition of distilled water to homogeneous liquid mixture of oil, surfactant and co-surfactant, at ambient temperature by water titration method.

From result of solubility studies and screening of solubility of excipient: Oleic acid, Capryol PGMC and ethanol were selected as oil, surfactant and co-surfactant. The mixture of oil and surfactant / co-surfactant $(\mathrm{S} / \mathrm{CoS})$ i.e $\mathrm{S}_{\text {mix }}$ at certain weight ratio were diluted with water in drop wise addition. Surfactant and co-surfactant mixture were mixed in different weight ratio at different $\mathrm{Km}$ value 1, 2, 3 ratio i.e. 1:1, 2:1, 3:1 (w/w). The oil and $\mathrm{S}_{\text {mix }}$ were mixed at ratio of 1:9, 2:8, 3:7, 4:6, 5:5, 6:4, 7:3, 8:2, 9:1 Figure 2, 3 and 4 . Slow titration with aqueous phase was done to each ratio of oil and $\mathrm{S}_{\text {mix }}$ and visual observation was carried out for transparency and flowability of nanoemulsion. The mixtures were examined for turbidity to transparency. Clear and isotropic mixtures were deemed to be within Nano emulsion region. On the other hand, the emulsion with coarse droplets or temporary emulsion exhibiting coalescence or creaming on terminating stirring was considered "bad". All the tests were performed in triplicate..$^{11,12}$

\section{Preparation of liquid SNEDDS}

The phase diagram was constructed at different $\mathrm{Km}$ values. The $\mathrm{Km}$ value at which nano-emulsion region obtained was selected for further studies. Three formulations were selected from this nano- emulsion region.

Oil, surfactant and co-surfactant were accurately weighed and mixed by gentle stirring. Based on solubility, formulation amount of garlic oil (100mg) was dispersed into mixture of oil and surfactant and co-surfactant. All the components were mixed by gentle stirring on 
Table 1: Composition of selected formulation.

\begin{tabular}{|c|c|c|c|c|}
\hline Batch code & Drug (mg) & Smix (ml) & Oil (ml) & Water (ml) \\
\hline Garlic F1 & 100 & 30 & 10 & 60 \\
\hline Garlic F2 & 100 & 40 & 10 & 50 \\
\hline Garlic F3 & 100 & 50 & 10 & 40 \\
\hline
\end{tabular}

magnetic stirrer until garlic oil was completely dissolved. Mixture was sealed in glass vial and stored at room temperature for further study. ${ }^{13}$ The composition of selected formulations showed in Table 1 and Figure 6.

\section{Evaluation of SNEDDS ${ }^{14-16}$ \\ Physical characterization}

The organoleptic properties of the SNEDDS such as, color, odor and physical state were checked by visual observation.

\section{Thermodynamic stability study}

The thermodynamic stability of lipid based formulation can be adversely affected by precipitation of the drug in the excipients matrix. This can be also lead to phase separation of the excipients affecting not only formulation performance as well as visual functioning. The thermodynamic stability study was based on following three tests:

\section{Heating and cooling cycle}

Three heating/cooling cycles between $4^{\circ} \mathrm{C}$ and $40^{\circ} \mathrm{C}$ with storage at each temperature for not less than 24 h. The resultant formulations were evaluated for their thermodynamic instability like precipitation and phase separation. The formulation which qualifies this test was subjected to further study.

\section{Centrifugation study}

The prepared formulations were centrifuged using laboratory centrifuge at $5000 \mathrm{rpm}$ for $30 \mathrm{~min}$. The resultant formulations were then determined for any instability problem, such as phase separation, cracking or creaming. A formulation which qualifies this test subjected for further study.

\section{Freeze thaw cycle}

To determine the stability of SNEDDS freeze thawing was employed. The prepared formulations were subjected to three freeze thaw cycles, which included freezing at $-4^{\circ} \mathrm{C}$ for $24 \mathrm{~h}$ followed by thawing at $40^{\circ} \mathrm{C}$ for $24 \mathrm{~h}$. Then centrifugation was performed at $3000 \mathrm{rpm}$ for $10 \mathrm{~min}$. Then the tested formulations were observed for phase separation.

\section{Rheological study}

The viscosity of the prepared formulations was determined by using Brookfield viscometer which determines the consistency of nano-emulsion formulation. $1 \mathrm{ml}$ of each prepared formulations were diluted 10 times with distilled water and then viscosity was measured using Brookfield viscometer and assessed visually for any phase separation.

\section{Globule size and zeta potential determination}

Droplet size of SNEDDS was determined by photon correlation spectroscopy that analyses the fluctuations in light scattering due to Brownian motion of the particle, using a Zetasizer. The zeta potential of the SNEDDS should be evaluated as it may further give an idea of the colloidal stability. Both these tests were carried out by using Nanoparticle analyzer sz-100 (Horiba Scientific, Japan).

\section{Dispersibility test (Assessment of self emulsification)}

The efficiency of self- emulsification of oral nanoemulsion is determined by using a standard USP XXII dissolution apparatus II. $1 \mathrm{ml}$ of each formulation is added to $500 \mathrm{ml}$ of water at $37 \pm 0.5^{\circ} \mathrm{C}$. The stainless steel dissolution paddle rotating at 50 RPM provided gentle agitation. The emulsification time assessed visually.

\section{Percent transmittance}

The percent transmittance of the prepared formulations were measured using UV Visible double beam spectrophotometer or Single Beam Spectrophotometer using distilled water as blank at suitable wavelength. For this study $1 \mathrm{ml}$ of each prepared formulations were diluted to $100 \mathrm{ml}$ of distilled water and observed for any turbidity and \% transmittance was observed by using UV-visible spectrophotometer (Shimadzu UV 1800) against distilled water at suitable wavelength.

\section{Cloud point determination}

The prepared formulations were diluted with distilled water in the ratio 1:250, placed in water bath and its temperature was increased gradually. Cloud point was measured at the temperature at which there was a sudden appearance of cloudiness occurred.

\section{Drug content}

The total amount of drug in the formulation was analyzed by dissolving the formulation in $10 \mathrm{ml}$ of 
methanol. This solution was vortexed for $10 \mathrm{~min}$ in vortex mixture. The mixture was centrifuged at 15,000 rpm for $10 \mathrm{~min}$. Then the supernatant was filtered through Whatman filter paper. The concentration of garlic oil was analyzed spectrophotometrically at $306 \mathrm{~nm}$.

\section{FTIR Study}

The prepared formulations were analyzed by Fourier Transform infrared spectroscopy (UV Agilent Technology) to characterize the probable structural modification produced. The sample was analyzed in the region of 4000 and $400 \mathrm{~cm}^{-1}$ and then sample or mixture kept into sample holder for analysis.

\section{In vitro drug release study}

In vitro dissolution studies of prepared formulations were carried out. The prepared formulations were filled in hard gelatin capsule. In vitro drug release profile of garlic oil from SNEDDS was assessed using USP dissolution testing apparatus I (basket type) at $50 \mathrm{rpm}$ with $900 \mathrm{ml} 0.05 \mathrm{M} \mathrm{NaCl}$ of $\mathrm{pH} 1.5$ as dissolution medium. Temperature was set at $37.0 \pm 0.5^{\circ} \mathrm{C}$ and sampling interval were fixed at $5,10,15,20,25,30$ min. $1 \mathrm{ml}$ of sample withdraw at each time interval and replaced with $1 \mathrm{ml}$ fresh $0.05 \mathrm{M} \mathrm{NaCl}$ of $\mathrm{pH} 1.5$ solution. The solution was immediately filtered through whatman filter paper and the filtrate was diluted with dissolution medium up to $10 \mathrm{ml}$ and evaluated for the drug content using UV-Visible spectrophotometric method at $306 \mathrm{~nm} .{ }^{17}$

\section{RESULTS AND DISCUSSION}

From the solubility study oleic acid was selected as oil, capryol PGMC as surfactant and ethanol as co-surfactant, as the garlic oil shows more solubility than the other components which were shown in Figure 1.

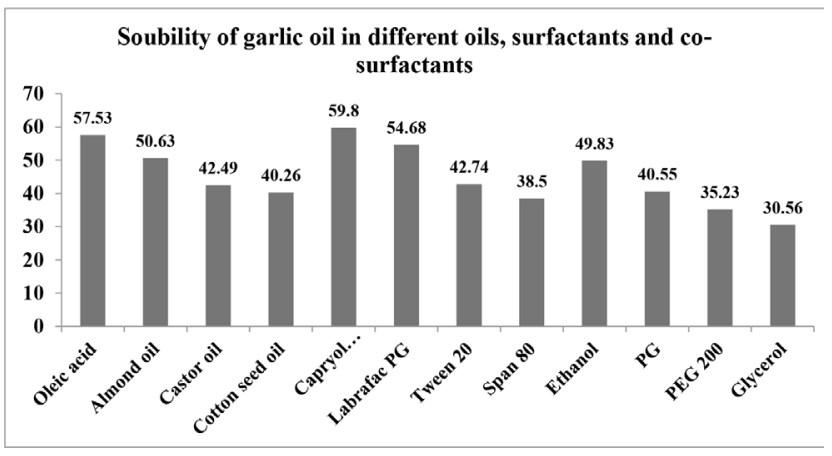

Figure 1: Solubility of garlic oil in different oils, surfactants and co- surfactants.

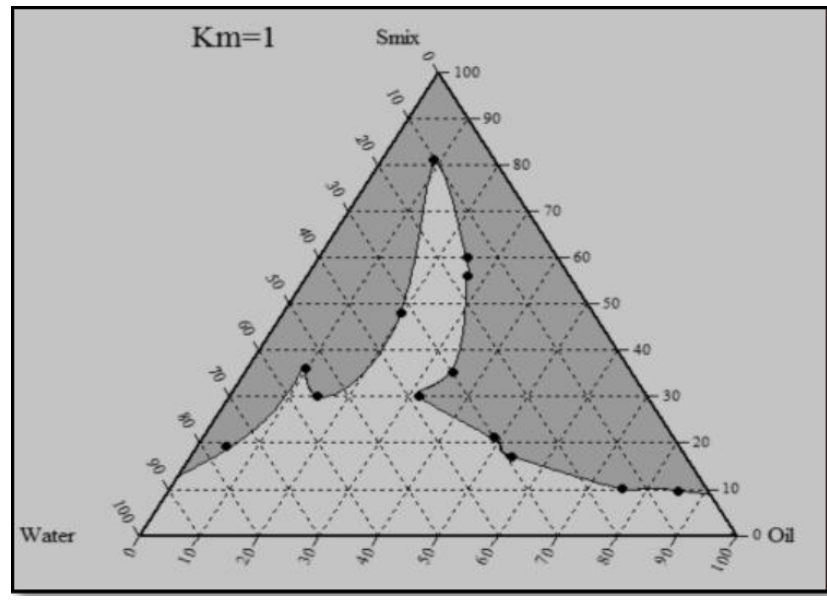

Figure 2: Ternary phase diagram of Oleic acid, Capryol PGMC, Ethanol at $\mathrm{Km}=1$.

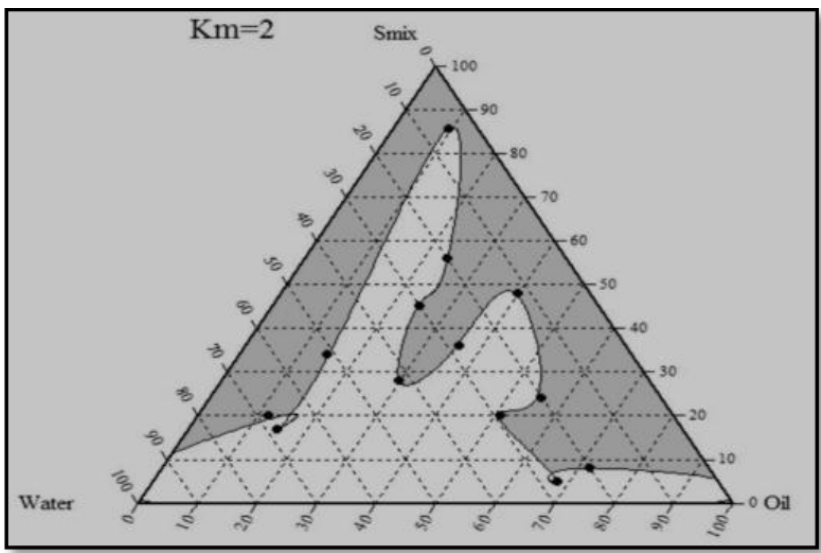

Figure 3: Ternary phase diagram of Oleic acid, Capryol PGMC, Ethanol at $\mathrm{Km}=2$.

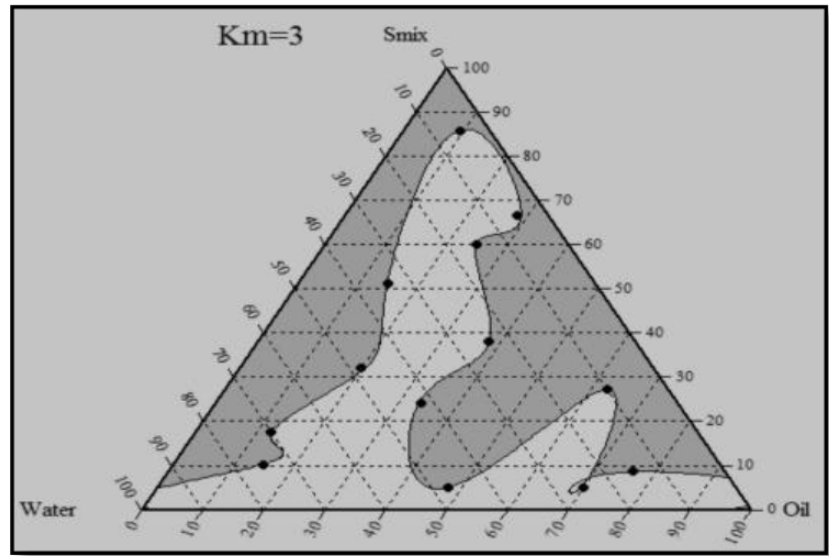

Figure 4: Ternary phase diagram of Oleic acid, Capryol PGMC, Ethanol at $\mathrm{Km}=3$. 


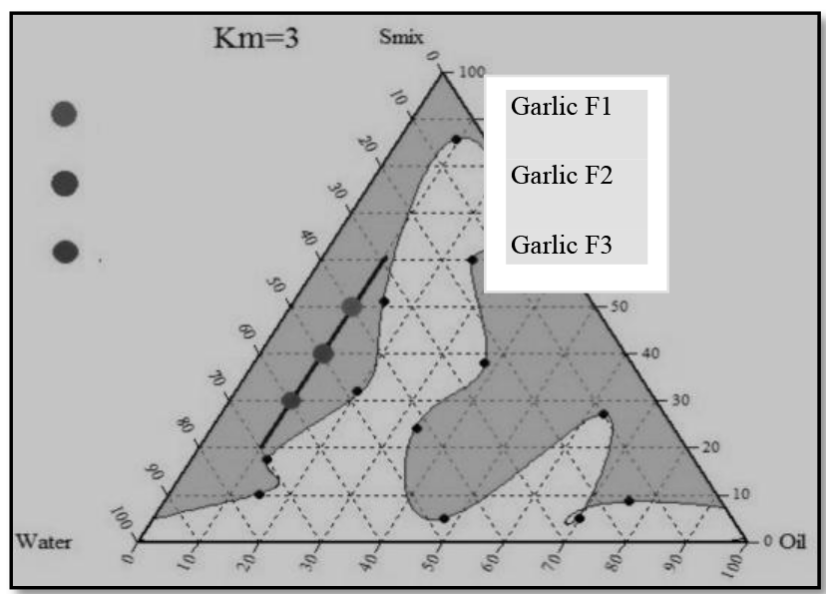

Figure 5: Selected composition of formulations Garlic F1 to Garlic F3.

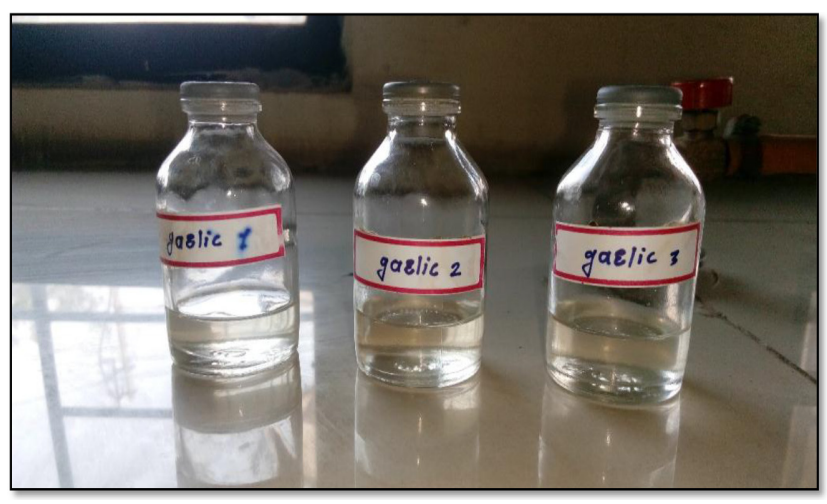

Figure 6: Formulated batches of SNEDDS of Garlic oil.

\section{Construction of pseudo-ternary phase diagram}

\section{Preparation of liquid Self Nano-emulsifying Drug Delivery System}

Oleic acid-Capryol PGMC-Ethanol-Water based system selected at final Pseudoternary phase diagram of various surfactants and co-surfactant weight ratio was constructed and system of highest water absorption (highest nano emulsion region) selected for formulation. The phase diagram at $\mathrm{Km}$ value 3 showed better nanoemulsion existence region than 1 and 2 .

Three formulations were selected from phase diagram at $\mathrm{Km}$ value 3, named as Garlic F1, Garlic F2, Garlic F3, as shown in Figure 5. Quantitative unit compositions of selected formulation of SNEDDS were presented in Table 2.

\section{Evaluation of prepared SNEDDS}

\section{Physical characterization}

The physical characterization of formulated batches was shown in Table 3.

\begin{tabular}{|} 
Table 2: Composition of selected formulations. \\
\hline Batch & Drug (mg) & Smix (ml) & Oil (ml) & Water (ml) \\
\hline F1 & 100 & 30 & 10 & 60 \\
\hline F2 & 100 & 40 & 10 & 50 \\
\hline F3 & 100 & 50 & 10 & 40 \\
\hline
\end{tabular}

\begin{tabular}{|c|c|c|}
\hline \multicolumn{3}{|c|}{ Table 3: Physical characterization of formulated } \\
batches.
\end{tabular}

\begin{tabular}{|c|c|c|c|}
\hline \multicolumn{4}{|c|}{ Table 4: Thermodynamic stability study of } \\
formulated batches. \\
\hline Batch & $\begin{array}{c}\text { Heating cooling } \\
\text { cycles }\end{array}$ & $\begin{array}{c}\text { Centrifugation } \\
\text { test }\end{array}$ & $\begin{array}{c}\text { Freeze thaw } \\
\text { cycles }\end{array}$ \\
\hline Garlic F1 & + & + & + \\
\hline Garlic F2 & + & + & + \\
\hline Garlic F3 & + & + & + \\
\hline
\end{tabular}

\section{Thermodynamic stability study}

Thermodynamic stability of SNEDDS was essential to its performance, which can be affected by precipitation of the drug. In addition the formulation having poor physical stability can affects the formulation performance and it also leads to phase separation. Hence thermodynamic stability studies were performed by performing heating cooling cycle, centrifugation test and freeze thaw cycle, it was observed that formulation passed the heating cooling cycle test, hence further exposed to centrifugation test then it was taken for freeze thaw stress test. After freeze thaw stress test it was found that all three formulations showed good stability with no phase separation, creaming or cracking were showed in Table 4.

\section{Rheological study}

The rheological properties of the prepared formulations were evaluated by Brookfield viscometer. This viscosities determination confirm the system is o/w or w/o. If system has low viscosity then it is $\mathrm{o} / \mathrm{w}$ and high viscosity then $\mathrm{w} / \mathrm{o}$. Viscosity of prepared batches was determined by diluting $1 \mathrm{ml}$ sample of each batch with $10 \mathrm{ml}$ and $100 \mathrm{ml}$ of distilled water by using Brookfield viscometer. The obtained results were showed in Table 5 .

\section{Globule size and zeta potential determination}

The globule size of the emulsion is a crucial factor of self nano-emulsification performance because it deter- 
mines the rate and extends of drug release as well as drug absorption. Also, smaller particle size of the emulsion droplets may lead to more rapid absorption and improve the bioavailability.

The globule size and zeta potential determined using Nanoparticle analyzer sz-100. The average globule size was taken into consideration. Table 6 shows the particle size, zeta potential and PDI of formulated batches of garlic oil SNEDDS diluted with water. The average particle size obtained from optimized batch Garlic F2 of SNEDDS formulation of garlic oil was found to be 177.2 $\mathrm{nm}$, zeta potential $-25 \mathrm{mv}$ and polydispersity index was found to be 0.386 Figure 7 and 8 . Zeta potential is the another property that was assessed for increased absorption of SNEDDS is the charge of oil droplets which is usually found to be negative due to the presence of free fatty acid. These results indicate that the optimal garlic oil SNEDDS formulation produced clear nano emulsion with nanometric size.

\section{Dispersibility test (Assessment of Self Emulsification)}

Emulsification time is a major parameter that helps in the determination of emulsification rate of SNEDDS. Oil is a major factor that affect relatively because when it present in high concentration, it prevent penetration of water. While hydrophilic compound such as surfactant and co-surfactant helps in dispersion and so enhance the emulsification rate. The efficiency of self- emulsification could be estimated primarily by determining the rate of oil droplets of SNEDDS formulation dispersed quickly and completely when subjected to aqueous dilution under agitation. The self- emulsification time of prepared formulation of SNEDDS were show in Table 7.

\section{Percent transmittance}

The results of $\%$ transmittance were shown in Table 8. The clarity of prepared nano emulsion was checked by transparency, measured in terms of transmittance. SNEDDS forms o/w nano emulsion since water is external phase. Formulation Garlic F2 has $97.50 \%$ transmittance. The result indicates good clarity of emulsion Table 8.

Cloud point determination Cloud point of prepared nanoemulsion was found to be higher than $80^{\circ} \mathrm{C}$, which indicate that nanoemulsion will be stable at physiological temperature without risk of phase separation. The obtained results were showed in Table 9 .

Drug content The drug content of the prepared formulations was shown in Table 10.
Table 5: Viscosity determination of formulated batches.

\begin{tabular}{|c|c|c|c|}
\hline \multirow{2}{*}{ Sr. No. } & \multirow{2}{*}{ Batch } & \multicolumn{2}{|c|}{ Viscosity $\mathbf{~ p ~}$} \\
\cline { 3 - 4 } & & $\mathbf{1 0} \mathbf{~ m l ~ d i l u t i o n ~}$ & $\mathbf{1 0 0} \mathbf{~ m l ~ d i l u t i o n ~}$ \\
\hline 1 & Garlic F1 & 0.5467 & 0.3589 \\
\hline 2 & Garlic F2 & 0.4043 & 0.3467 \\
\hline 3 & Garlic F3 & 0.5689 & 0.3654 \\
\hline
\end{tabular}

Table 6: Globule size, Zeta potential and PDI of prepared formulations.

\begin{tabular}{|c|c|c|c|c|}
\hline $\begin{array}{c}\text { Sr. } \\
\text { No. }\end{array}$ & Batch & $\begin{array}{c}\text { Average Particle } \\
\text { size (Droplet size } \\
\text { /Globule size }\end{array}$ & $\begin{array}{c}\text { Zeta } \\
\text { potential }\end{array}$ & $\begin{array}{c}\text { Poly- } \\
\text { dispersity } \\
\text { index (PDI ) }\end{array}$ \\
\hline 1 & Garlic F1 & $185.00 \mathrm{~nm}$ & $-20 \mathrm{mv}$ & 0.567 \\
\hline 2 & Garlic F2 & $177.2 \mathrm{~nm}$ & $-25 \mathrm{mv}$ & 0.386 \\
\hline 3 & Garlic F3 & $193.90 \mathrm{~nm}$ & $-18 \mathrm{mv}$ & 0.690 \\
\hline
\end{tabular}

Table 7: Self-emulsification time of prepared formulation.

\begin{tabular}{|c|c|c|}
\hline Sr. No. & Batch & Emulsification time ( sec ) \\
\hline 1 & Garlic F1 & $59.83 \pm 0.76$ \\
\hline 2 & Garlic F2 & $70.30 \pm 0.49$ \\
\hline 3 & Garlic F3 & $60.36 \pm 0.28$ \\
\hline
\end{tabular}

Table 8: \% Transmittance of prepared formulations.

\begin{tabular}{|c|c|c|}
\hline Sr. No. & Batch & \% Transmittance \\
\hline 1 & Garlic F1 & $92.71 \pm 0.25$ \\
\hline 2 & Garlic F2 & $97.50 \pm 0.40$ \\
\hline 3 & Garlic F3 & $95.33 \pm 0.41$ \\
\hline
\end{tabular}

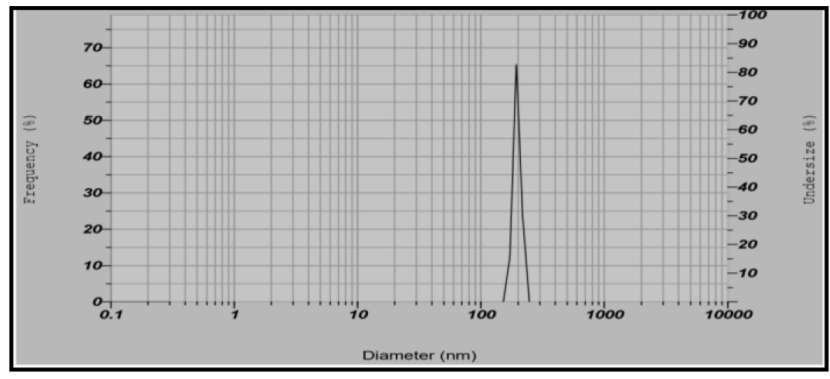

Figure 7: Globule size analysis of optimized batch Garlic F2.

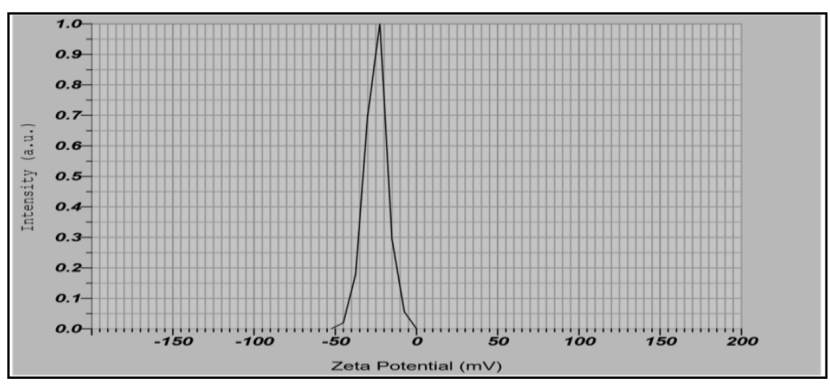

Figure 8: Zeta potential of optimized batch Garlic F2. 
Table 9: Cloud point determination of prepared formulation

\begin{tabular}{|c|c|c|}
\hline Sr. No. & Batch & Cloud point \\
\hline 1 & Garlic F1 & More than $80^{\circ} \mathrm{C}$ \\
\hline 2 & Garlic F2 & More than $95^{\circ} \mathrm{C}$ \\
\hline 3 & Garlic F3 & More than $90^{\circ} \mathrm{C}$ \\
\hline
\end{tabular}

Table 10: Drug content of prepared formulations.

\begin{tabular}{|c|c|c|}
\hline Sr. No. & Batch & \% Drug content \\
\hline 1 & Garlic F1 & $75.05 \pm 0.55$ \\
\hline 2 & Garlic F2 & $90.89 \pm 0.68$ \\
\hline 3 & Garlic F3 & $67.98 \pm 0.75$ \\
\hline
\end{tabular}

Table 11: \% Drug release of prepared formulations.

\begin{tabular}{|c|c|c|}
\hline Sr. No. & Batch & \% Drug release \\
\hline 1 & Garlic F1 & 85.78 \\
\hline 2 & Garlic F2 & 98.85 \\
\hline 3 & Garlic F3 & 90.78 \\
\hline
\end{tabular}

\section{FTIR study}

Drug and formulation has shown no any difference in spectra indicate drug is intact in the formulation which was shown in Figure 9.

\section{In vitro drug release}

In vitro drug release study of prepared formulations of garlic oil SNEDDS was performed in $0.05 \mathrm{M} \mathrm{NaCl}$ of $\mathrm{pH} 1.5$. The $\%$ drug release was shown in Table 11 and Figure 10.

\section{CONCLUSION}

In this study, liquid SNEDDS was formulated by using capryol PGMC as surfactant. From this study, it was concluded that the prepared liquid SNEDDS was thermo dynamically stable with good self-emulsification efficiency, improved dissolution rate and having globule size in the nanometric range which may be physiologically stable. The SNEDDS with relatively high drug content was prepared which self-emulsified easily with mean emulsion droplet size of $177.2 \mathrm{~nm}$. Thermodynamic stability study and cloud point study confirmed that the SNEDDS had no dilution effect and was stable without any precipitation of drug and without any change in emulsion droplet size.

\section{ACKNOWLEDGEMENT}

The authors are thankful to Ashokrao Mane College of Pharmacy management for providing facility to carry

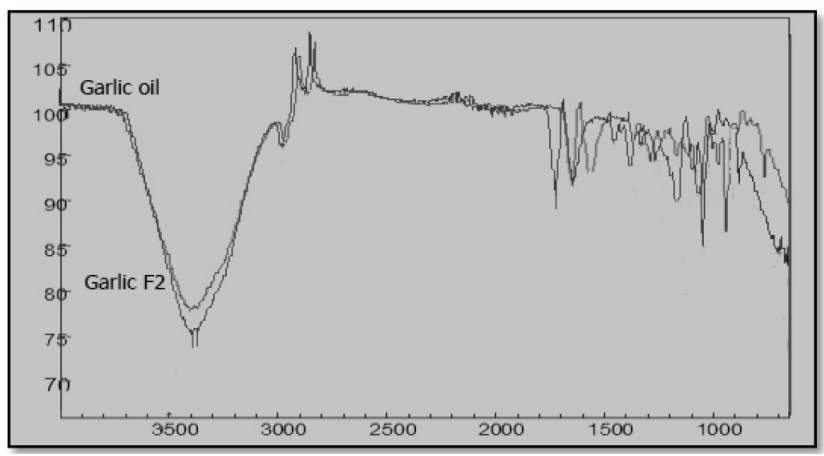

Figure 9: FTIR Spectra of garlic oil and optimized batch F2.

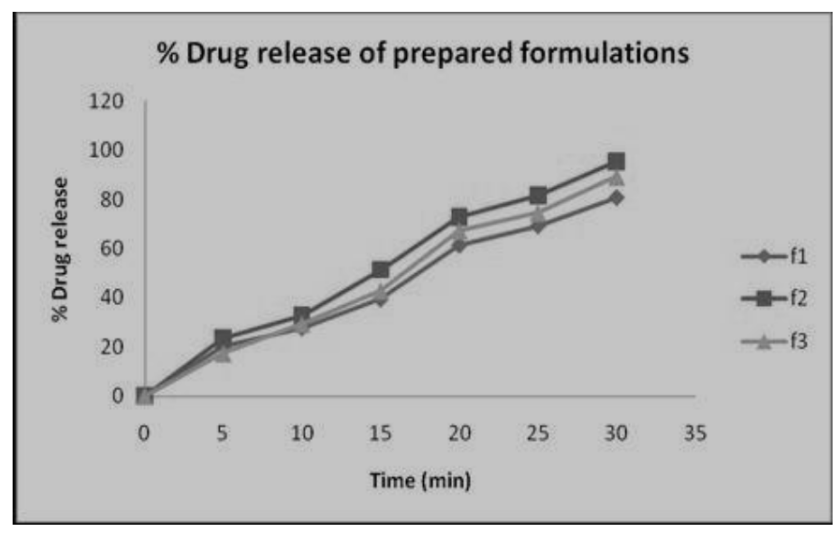

Figure 10: \% Drug release of prepared formulations.

out research work, also thankful to Sanket Enterprises, Mumbai for providing Garlic Oil and Gatteffosse Mumbai for providing Capryol PGMC as gift sample.

\section{CONFLICT OF INTEREST}

The authors declare no conflict of interest.

\section{ABBREVIATIONS}

FTIR: Fourier Transform Infrared Spectrometer; SNEDDS: Self Nanoemulsifying Drug Delivery System; RPM: Revolutions per Minute; PGMC: Propylene Glycol Monocaprylate.

\section{REFERENCES}

1. Bhandari PR. Garlic (Allium sativum L.): A review of potential therapeutic applications. International Journal of Green Pharmacy. 2012;6:118-29.

2. Orekhov AN, Grunwald J. Effects of garlic on atherosclerosis. Nutrition. 1997;7(8):656-63.

3. Jain RC, Konar DB. Effect of garlic oil in experimental cholesterol atherosclerosis. Atherosclerosis. 1978;29(2):125-9.

4. Kuruvila FS, Mathew F, Kuppu SS. Solid Self Nanoemulsifying Drug Delivery System (SNEDDS) Development, Applications and Future Perspective: A Review. Indo American Journal of Pharmaceutical Sciences. 2017;4(3):651-69.

5. Date AA, Desai N, Dixit R, Nagarsenkar M. Self nanoemulsifying drug delivery systems: formulation insights applications and advances. Nanomedicine. 2015;5(10):616-26. 
6. Mistry RB, Seth NS. A Review: Self Emullsifying Drug Delivery System. International Journal of Pharmacy and Pharmaceutical Sciences. 2011;3(2):23-8.

7. Nigade PM, Patil SL, Tiwari SS. Self-Emulsifying Drug Delivery System (SEDDS): A review. International Journal of Pharmacy and Biological Science. 2012;2(2):42-52.

8. Bordia A, Verma SK, Srivastava KC. Effect of garlic (Allium sativum) on blood lipids, blood sugar, fibrinogen and fibrinolytic activity in patients with coronary artery disease. Prostaglandins Leukot Essent Fatty Acids. 1998;58(4):257-63.

9. Davis SR. An overview of the antifungal properties of allicin and its breakdown products the possibility of a safe and effective antifungal prophylactic. Mycoses. 2005;48(2):95-100

10. Zaho Y, Wang C, Chow AHL, Ren K, Gong T, Zang Z, et al. Self Nanoemulsifying Drug Delivery System for Oral Delivery of Zedoary Essential Oil: Formulation and Bioavailability Studies. International Journal of Pharmaceutics. 2010;383(1-2):170-7.

11. Shafiq S, Shakeel F, Talegaonkar S, Ahmad FJ, Khar RK, Ali M. Development and bioavailability assessment of ramipril nanoemulsion formulation. European Journal of Pharmaceutics and Biopharmaceutics. 2007;66(2):227-43.
12. Wang L, Dong J, Chen J, Eastoe J, Li X. Design and optimization of a new self nanoemulsifying drug delivery system. Journal of Colloid and Interface Science. 2009;330(2):443-8.

13. Nasar A, Gardouh A, Ghorab M. Novel Solid Self Nanoemulsifying (S-SNEDDS) for Oral Delivery of Olmesartan Medoxomil: Design, Formulation, Pharmacokinetic and Bioavailability Evaluation. Pharmaceutics. 2016;8(20):1-29.

14. Udaya SM, Lobo JR, Uppuluri KB. Self Nanoemulsifying Drug Delivery Systems for Oral delivery of Hydrophobic Drugs. Biomedical and Pharmacology Journal. 2013;6(2):355-62.

15. Damineni S, Penjuri SCB, Ravoru N. Formulation and Evaluation of Self Nanoemulsifying Drug Delivery System of Naproxen. International Journal of Pharmaceutical Biosciences and Nanotechnology. 2015;8(1):2715-22.

16. Narkhede RS, Gujar KN, Gambhire VM. Design and Evaluation of Self Nanoemulsifying Drug Delivery Systems form Nebivolol Hydrochloride. Asian Journal of Pharmaceutics. 2014;8(3):200-9.

17. Wang J, Cao Y, Sun B, Wang C. Physicochemical and release characterization of garlic oil- $\beta$-cyclodextrin inclusion complexes. Food Chemistry. 2011;127(4):1680-5.

\section{PICTORIAL ABSTRACT}

Problems associate with Garlic oil: Volatility, Strong odour, Insolubility in water, Low physicochemical stability

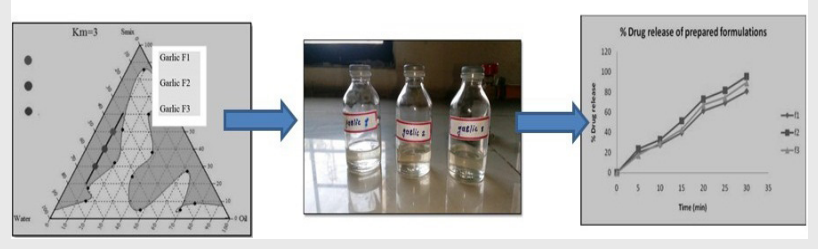

\section{About Authors}

Ms. Priyanka C. Sangar, has completed B Pharm and M Pharm in Pharmaceutics from Ashokrao Mane College of Pharmacy, Peth Vadgaon in 2018. Currently, he is working as Assistant Professor at Yashoda Technical Campus, Satara.

Mr. Sandip A. Bandgar, has completed B Pharm in 2004 and M. Pharm (Biopharmaceutics) in 2008 from Government College of Pharmacy, Karad and pursuing his Ph.D from Shivaji University, Kolhapur. Presently, he is working as Assistant Professor and PG Teacher, Department of Pharmaceutics, Ashokrao Mane College of Pharmacy, Peth Vadgaon. He has 2 years of diploma and 11 years of degree teaching experience. He has published 10 research articles in reputed national and international journals and 4 books on his credit. He has presented various research papers in national and international level conferences and workshops. He is a life member of various professional associations like APTI, MSPC and KPSF.

Mr. Sardar S. Shelake, has completed M.Pharm from Ashokrao Mane College of Pharmacy, Peth Vadgaon in Pharmaceutics. He has qualified GPAT in 2013. Presently he is perusing Ph.D. in Shivaji University, Kolhapur. Currently, he is working as Assistant Professor, Ashokrao Mane Institute of Pharmacy, Ambap. He has published 15 research and 5 review articles in reputed journals and 2 book chapters. He has 1 year at diploma level, 4 years at UG teaching experience. He is affiliated with professional bodies like MSPC. 
Mr. Pravin S. Patil, has completed MPharm. from Govt. College of Pharmacy, Karad in Biopharmaceutics. He has qualified GATE in 2003 and 2004. Presently he is perusing PhD. in Shivaji University, Kolhapur. Presently, he is working as Assistant Professor and PG Head, Ashokrao Mane College of Pharmacy, Peth Vadgaon. He has published 10 research and 3 review articles in reputed journals. He has 2 years at diploma level, 11 years at UG and PG teaching experience. He is affiliated with professional bodies like MSPC, APTI and KPSF.

Dr. D. A. Bhagwat, has completed his B. Pharm. in 2006 from BVCP, Kolhapur, M. Pharm. in Industrial Pharmacy from S. N. Institute of Pharmacy, Pusad in 2008 and Ph.D. from JJT, University, Rajasthan in 2014. He has total 11 years of Teaching Experience. Currently he is working as Assistant Professor Dept. of Pharmaceutics, Bharati Vidyapeeth College of Pharmacy, Kolhapur. He has authored Six books and published 42 research papers in national and international journals and presented more than 60 papers in various national and international conferences. He is life member of IPA and APTI. He has delivered many lectures in Patient Counseling Course conducted by MSPC, Mumbai.

Dr. Shitalkumar S. Patil, M. Pharm. PhD., MBA presently working as Principal, Ashokrao Mane College of Pharmacy, Peth Vadgaon. He has total 29 years of teaching experience. He has authored 5 books and published more than 75 research article in national and international journals. He is life member of APTI. He is a member of Board of Studies, Shivaji University, Kolhapur.

Cite this article: Sangar P, Sandip B, Sardar S, Pravin P, Durgacharan B, Shitalkumar P. Design, Development and Evaluation of Self Nanoemulsifying Drug Delivery System of Garlic Oil using Capryol PGMC. Indian J of Pharmaceutical Education and Research. 2019;53(4s):s539-s547. 